\title{
ADSA® Presidential Report
}

\section{Bob Roberts}

The Pennsylvania State University

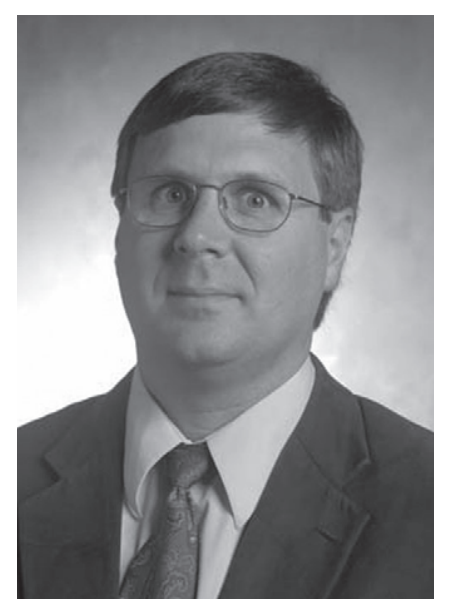

First, I want to thank the membership of ADSA for allowing me to serve as president of the association for the past year. It was both an honor and a pleasure to be able to work with the membership as well as with the talented and committed staff of our organization.

\section{Journal of Dairy Science}

By Thomson-Reuters Impact Factor, JDS was ranked second of 55 journals in the Agriculture, Dairy, and Animal Science category for 2011, and continues to be ranked number 1 by 5 -Year Impact Factor. The journal was also ranked number 1 by Eigenfactor (which removes self-citations) in the same category. The journal ranked 17th of 128 journals in the Food Science and Technology category, and 19th in this category by 5 -Year Impact Factor. The size of JDS increased from 634 articles and 6,022 (science) pages in 2010 to 640 articles and 6,258 (science) pages in 2011. Submissions to JDS remain strong and, notably, $70 \%$ of submissions are from international authors. A tremendous thank you to Roger Shanks for his work as editor-in-chief and to the editors, members of the editorial board, and reviewers. I also extend thanks to Susan Pollock, Louise Adam, Armgard Haken, Sharon Frick, Gayle Gleichman, Jorge Cazares, and other staff in the FASS office for their tireless work on the journal.

\section{Joint Annual Meeting}

The 2011 Joint Annual Meeting (JAM) in New Orleans was a very successful meeting, setting records for attendance at two-society meeting and number of abstracts submitted and accepted. In addition, JAM 2011 remained in a strong financial position, and over $50 \%$ of the attendees at JAM 2011 were members of ADSA! Registration for JAM 2012 in Phoenix was very strong and exceeded 3,000 registrants, approximately $50 \%$ of whom were members of ADSA. Special thanks to the program committee members, who work to deliver such an impressive meeting.

\section{Membership}

Individual memberships increased by 390 (10.9\%) over the year, due in large part to very strong growth in graduate student membership. Professional membership increased by $1.8 \%$. In addition, e-membership, a limited membership option available to scientists outside North America, is gaining traction (35 as of December 31, 2011).

In an effort to develop an understanding of member needs and satisfaction, ADSA commissioned a survey of the professional membership in 2011. The vast majority of members responding indicated they were extremely or somewhat satisfied ( $90.5 \%$ of total respondents) on a 5 -point scale. We will be using the responses from the open-ended questions contained in the survey to inform our strategic planning process in July. With the caveat that "we can always do better," I think this is a good report card from a key segment of the membership.

The ADSA Graduate Student Division (GSD) was successfully launched at the 2011 JAM. This group has shown tremendous initiative and energy. Following discussions with the student leadership, the ADSA Board of Directors approved a transitional membership to students as they graduate and move into their first professional position. Inaugural GSD President Katy Proudfoot did a magnificent job getting the GSD organized and moving forward, and we are looking forward to watching this group grow and mature over the next few years. 


\section{S-PAC}

S-PAC continues to grow, with ever more contributing conferences (45) and proceedings (420). Nine academic libraries now subscribe to S-PAC via an IP address range subscription type (as requested by some libraries). Some faculty members have reported they are using S-PAC in their coursework, and we are investigating that model to see if it can be offered to others. Importantly, S-PAC has more than recovered all the costs of developing and maintaining the system and operated solidly in the black for 2011. Any income from S-PAC contributes to growth of the ADSA Foundation's net assets. The time and continuing effort to develop, improve, and market S-PAC is paying off.

\section{Science Policy and Outreach}

ADSA continues to support FASS Science Policy Committee initiatives and has been active in several other areas including our spokesperson program, development of a LinkedIn site, publication of the weekly ADSA Dair-e-News, and development of strategic alliances with several professional societies and trade organization. These activities are supported by the work of Ken Olson. In addition, ADSA has been a signatory on several letters to government officials brought to us primarily by the FASS Science Policy Committee. Outgoing ADSA board member Karen Plaut will serve as chair of the FASS Science Policy Committee for 2012-2013.

\section{Discover Conferences}

Discover Conferences continue to be fully subscribed. The 2011 offerings-Discover 21: Improving
Reproductive Efficiency of Lactating Dairy Cattle, and Discover 22: Milk Components: Opportunities for Maximizing Farm Gate Returns and Meeting Manufacturing Needs - received excellent evaluations from a global set of participants. Thanks to Larry Miller for excellent leadership and highly effective program and business management, and to Molly Kelley for her excellent meeting planning and general support.

\section{The Numbers}

ADSA is in a strong financial position. Even while holding the line on dues and JAM registration rates, total revenues exceeded budget projections by $14 \%$ and expenses came in at budget (1\% over). Although we, like everyone, took a hit in our investment accounts, the audited financial report indicated total assets at the end of the year of $\$ 6,048,927$ and total net assets of $\$ 5,507,937$.

Financial performance for the ADSA Foundation was also very good. Net assets of the Foundation increased by $\$ 39,291$ in 2011 . This puts Foundation total assets at an all-time high of $\$ 624,047$, as of December 31, 2011.

\section{Summary}

ADSA remains a scientifically strong and active organization. The sound financial position of the organization will allow us to initiate additional programs and membership benefits in the future. I am pleased with the vibrancy of the new Graduate Student Division, which indicates that the future of our organization is in very good hands. 